\title{
KIM-1 Mediates High Glucose-Induced Autophagy and Apoptosis in Renal Tubular Epithelial Cells
}

\author{
Rong Gou Juntong Chen Shifeng Sheng Ruiqiang Wang Yudong Fang \\ Zijun Yang Liuwei Wang Lin Tang
}

Department of Nephropathy, the First Affiliated Hospital of Zhengzhou University, Zhengzhou, P.R.China

\section{Key Words}

Diabetic nephropathy $\bullet$ LC3II $\bullet$ Autophagosome $・$ Renal fibrosis

\begin{abstract}
Background/Aim: To investigate the role of kidney injury molecular 1 (KIM-1) in high glucoseinduced autophagy and apoptosis in renal tubular epithelial cells. Methods: Human renal tubular epithelial cells (HK2) were treated with normal glucose (NG, D -glucose $5.6 \mathrm{mmol} / \mathrm{L}$ ), high glucose (HG, $30 \mathrm{mmol} / \mathrm{L})$, high osmotic (HO, D-glucose $5.6 \mathrm{mmol} / \mathrm{L}+\mathrm{D}$-mannitol 24.4 mmol/L), HG + KIM-1 siRNA, HG + siRNA control. The expressions of KIM-1 and microtubuleassociated protein 1 light chain 3II (LC3II) were measured by western blot as well as real time PCR; the number of autophagosome was detected by electron microscopy; and the level of apoptosis was analyzed by flow cytometry. Results: In the HG group, the expressions of KIM1 and LC3II were increased markedly, which was accompanied by more autophagosome and higher level of apoptosis compared with NG group. Silencing of KIM-1 by siRNA inhibited the increases in the levels of LC3II, autophagosome and apoptosis. Conclusion: KIM-1 may mediate high glucose-induced autophagy and apoptosis in renal tubular epithelial cells.
\end{abstract}

(C) 2016 The Author(s)

Published by S. Karger AG, Basel

\section{Introduction}

Diabetic nephropathy (DN), as one of the most serious complications of diabetes mellitus, is the main cause of end-stage renal failure (ESRD). However, effective treatment for reducing proteinuria and delaying progression of renal tubulointerstitial fibrosis is lack. Therefore, it is imperative to investigate the mechanisms and explore new effective preventive or therapeutic protocol. DN is characterized by gradual development of renal tubulointerstitial fibrosis, and that the lesion of renal interstitium is a better predictor of 
progression of kidney damage compared with the glomerular injury [1-3]. The balance between the survival and death of renal tubular epithelial cells plays a crucial role in the lesion of renal interstitium [4]. Studies have shown that high glucose-induced apoptosis in renal tubular epithelial cells, which leads to tubular atrophy and dysfunction, is a critical process of tubulointerstitial fibrosis [5, 6]. KIM-1 is a transmembrane glycoprotein expressed by injured proximal tubular epithelial cells. It is considered as a sensitive and specific marker of renal tubular epithelial injury [7-9]. It is also a factor involved in the progression of kidney disease [10-12]. The expression of KIM-1 is elevated in patients with diabetic nephropathy $[13,14]$. However, the role of KIM-1 in DN is unknown. The expression of KIM-1 is in relation to Cadmium-induced apoptosis in proximal tubule injury [15], indicating that KIM-l may be involved in the processes of injury and repair of the renal tubular epithelium.

Autophagy is an evolutionarily conserved processes that maintains intracellular homeostasis and cell integrity. However, autophagy may also represent a form of programmed cell death, which is highly interconnected with apoptosis. The crosstalk between apoptosis and autophagy is complex, as they share many key regulators [16] and that increased autophagy can promote apoptosis [17]. Apoptosis is an ordered and orchestrated cellular process that occurs in physiological and pathological conditions. It is also involved in the pathogenesis of DN [18]. Studies have shown that high glucose-induced apoptosis in renal tubular epithelial cells, which leads to tubular atrophy and dysfunction, is a critical process of tubulointerstitial fibrosis $[6,19]$. Meanwhile, impaired autophagic activity is also involved in the development of chronic kidney diseases (CKD) including DN [20,21].

Recent reports have indicated that KIM-1 can function as a regulator of transforming renal tubular epithelial cells into semi-professional phagocytes, increasing the level of autophagy [22]. It remains unknown whether KIM-1 is involved in high glucose-induced autophagy and apoptosis in renal tubular cells. The present study aims to test the hypotheses that KIM-1 is the mediator in high glucose-induced autophagy and apoptosis in HK2 cells. We first evaluated the effects of high glucose on the expression of KIM-1 as well as the induction of autophagy and apoptosis in HK2 cells, a human proximal tubular cell line. We then investigated the effect of KIM-1 siRNA on these pathological changes. Our results for the first time demonstrate that KIM-1 mediates high glucose-induced damage in renal tubular cells.

\section{Materials and Methods}

\section{Materials}

Human renal tubular epithelial cell (HK2, China Center for Type Culture Collection), murine monoclonal anti-KIM-1 (Abcam,USA), rabbit polyclonal anti-LC3II (Abcam,USA), horse-radish peroxidase (HRP) labeled anti-rabbit and anti-rat secondary antibody (Zhongshanjinqiao, Beijing), donkey-cyanine 3 (CY3) labeled anti-rabbit and anti-murine secondary antibody (Sangon, shanghai), KIM-1 siRNA (Genepharma, Shanghai), apoptosis kit (KeyGen, Nanjing), Lipofectamine 2000 (Invitrogen, USA), fetal calf serum (BI, Israel), DMEM culture medium (Hyclone, USA) and PCR primers (GeneCopoeia, USA).

\section{Cell culture and treatment}

HK2 cells were cultured in Dulbecco's modified Eagle's medium (DMEM) supplemented with 5.6 mM D-glucose, 10\% fetal bovine serum (FBS), $100 \mathrm{U} / \mathrm{ml}$ penicillin, and $100 \mu \mathrm{g} / \mathrm{ml}$ streptomycin in a $5 \% \mathrm{CO} 2$ incubator at $37^{\circ} \mathrm{C}$. The medium was routinely replaced every 3-4 days. When growing to more than $80 \%$ confluence, cells were trypsinized, plated in 6-well culture plates at a density of $1 \times 10^{6} / \mathrm{ml}$. When growing to $70-80 \%$ of fusion, cells were synchronized with serum-free medium for 12 hours and then used for experiments. Treatments of cells in different experiment groups were described in results.

SiRNA transfection cells

The sequence of KIM-1 siRNA: sense, 5-UUG AUA ACT UGA ACA GAU AAT-3; antisense, 5-CAU UUG UUC ACG CUA UCA GTT-3 (synthesized by Jikai Gene Chemical Technology, Shanghai, China). A scrambled 


\section{Cellular Physiology Cell Physiol Biochem 2016;38:2479-2488 \begin{tabular}{l|l} 
and Biochemistry Published online: June 17, 2016 & $\begin{array}{l}\text { C } 2016 \text { The Author(s). Published by S. Karger AG, Basel } \\
\text { www.karger.com/cpb }\end{array}$
\end{tabular} \\ Gou et al.: KIM-1, Autophagy and Diabetic Nephropathy}

small RNA provided by this company was used as control for siRNA experiments. Transfection of siRNA was performed using Lipofectamine 2000 according to the manufacturer's instructions.

\section{Western blot analysis}

The cells were harvested and lysed in RIPA buffer with protease and phosphatase inhibitors, centrifuged at $12,000 \mathrm{rpm}$ for $20 \mathrm{~min}$ at $4^{\circ} \mathrm{C}$, and the supernatant measured for protein concentration. Protein samples were then mixed with loading buffer and boiled at $95-100^{\circ} \mathrm{C}$ for $5 \mathrm{~min}$. Total protein extracts were subjected to $12 \%$ SDS-PAGE. The separated proteins were transferred on polyvinylidene fluoride membranes by electrotransfer. The blots were subsequently blocked with 5\% skimmed milk and incubated with antibody against KIM-1 (1:500 dilution), LC3B (1:500 dilution) or $\beta$-actin (1:1000 dilution) for $12 \mathrm{~h}$ at $4^{\circ} \mathrm{C}$. The membranes were washed and then incubated with horseradish peroxidase-linked, goat anti-rabbit or horse anti-mouse IgG (1:500 dilution) at room temperature for 2 h. 3, 3'-Diaminobenzidine(DAB)(Sigma Chemicals, Missouri) was used as the horseradish peroxidase substrate for membrane color development. The densitometric analysis was conducted with ChemiDoc MP Imaging System (BIO-RAD). Each band normalized to $\beta$-actin presented the relative density values.

\section{Real Time-PCR analysis}

Total RNA of HK2 cells was extracted using Trizol and reverse transcribed (RT). Real-time PCR analysis of the RT products was performed on a DNA Engine Opticon TM system (Fuzhong Bio-Company, Shanghai, China). The reactions were incubated in a 96 -well plate at $95^{\circ} \mathrm{C}$ for $10 \mathrm{~min}$, followed by 40 cycles at $95^{\circ} \mathrm{C}$ for $15 \mathrm{~s}$ and $60^{\circ} \mathrm{C}$ for $1 \mathrm{~min}$. All reactions were run in triplicate. As an internal control, levels of glyceraldehyde-3phosphate dehydrogenase (GAPDH) were quantified in parallel with target genes. Normalization and fold changes were calculated using the $\Delta \Delta \mathrm{Ct}$ method. Relative mRNA levels were expressed by the values of $2^{-\Delta \Delta C t}$. PCR was conducted with specific primers for the following mRNAs: KIM-1 F: GAC AGA GTC TTC AGA TGG CCT, R: GAG CAA GAA GCA CCA AGA CAG; LC3B F: AAG GCG CTT ACA GCT CAATG, R: CTG GGA GGC ATA GAC CATGT; GAPDH F: GTG GAC CTG ACC TGC CGTCT, R: GGA GGA GTG GGT GTC GCTGT (GeneCopoeia Inc,Rockville, Md, USA).

\section{Immunofluorescence analysis}

For indirect immunofluorescence, cells cultured on glass coverslips were washed twice with PBS, fixed with $4 \%$ paraformaldehyde for 30 minutes at room temperature. Cells were permeabilized with $0.1 \%$ Triton-X-100 for $10 \mathrm{~min}$, and then blocked with 1\% bovine serum albumin for 1 hour. Cells were incubated overnight with anti-KIM-1 (1:100) primary antibodies, which were subsequently detected with CY3-labeled anti-murine secondary antibody (1:500). Cells were then washed twice with PBS, counterstained with 4, 6-diamidino-2 phenylindole $(1 \mu \mathrm{g} / \mathrm{ml})$ for 5 minutes and washed twice again with PBS before mounting with fluorescence mounting medium.

\section{Electron microscopy}

The HK2 cells were fixed in $2.5 \%$ glutaraldehyde for $1 \mathrm{~h}$ and dissolved in $0.1 \mathrm{M}$ phosphate buffer (PB; pH 7.4). Cells were then post-fixed for $1 \mathrm{~h}$ in $1 \%$ osmium tetroxide in PB and stained with $70 \%$ ethanol containing 1\% uranyl acetate, which were subsequently dehydrated in a graded alcohol series and embedded in epon. Ultrathin sections were cut using a diamond knife, and then counterstained with 3\% uranyl acetate and $0.2 \%$ lead citrate (Sigma-Aldrich). The sections were visualized under transmission electron microscope (JEOL JEM-1400, Japan).

Flow cytometry for apoptosis assay

The HK2 cells were collected and incubated with propidium iodide (PI) and Annexin V (Biolegend), and analyzed by flow cytometry (BD Bioscience, USA).

\section{Statistical analyses}

Data was expressed as mean \pm standard deviation. Multiple comparisons were subjected to one-way analysis of variance (ANOVA). LSD test was used to evaluate statistical significance of differences between two groups. $\mathrm{P}<0.05$ was considered statistically significant. 


\section{Result}

Effect of high glucose on KIM-1 expression in HK2 cells

The levels of KIM-1 in cells treated with normal glucose and hypertonic condition were low and had no significant difference between these two groups. However, the HK-2 cells cultured in a high concentration of glucose showed significantly increased levels of KIM-1 (Fig. 1A). Western blotting and real time-PCR analysis showed that high glucose enhanced KIM-1 expression in a time-dependent manner (Fig. 1B and 1C).

Fig. 1. Effect of high glucose on KIM-1 expression in HK2 cells. (A) Representative photomicrographs showing immunofluorescence of KIM1 in different groups (100x). (B) Western Blot analysis of KIM1 protein levels at 8, 16 and 24 h. (C) Real time PCR analysis of KIM-1 mRNA levels. ${ }^{\mathrm{a}} \mathrm{p}<0.05$ compared with normal control group; ${ }^{b} p<0.05$ compared with the previous group $(\mathrm{n}=3)$.

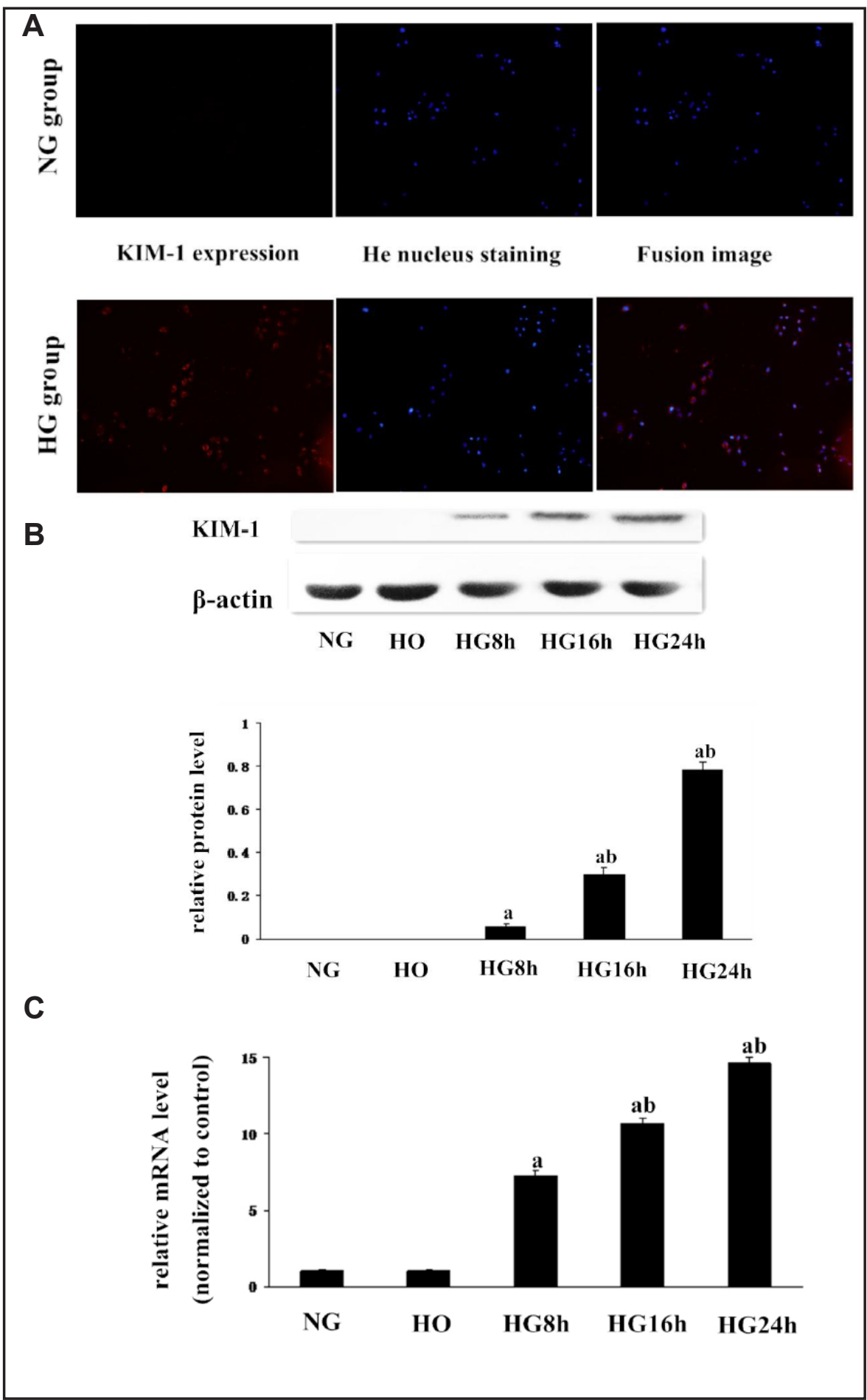


Effect of high glucose on autophagy and apoptosis in HK2 cells

Western blotting and real time-PCR analysis showed a time-dependent increase in the expression of the autophagic markers, LC3-II (Fig. 2A and 2B). Electron microscopy analysis showed a time-dependent accumulation of autophagosomes (Fig. 2C, black arrows), and flow cytometry showed a time-dependent increase of apoptosis rate (Fig. 2D), demonstrating a promotion of autophagy and apoptosis by exposure of the HK-2 cells to high glucose. However, the HK-2 cells incubated in medium with high osmotic had no significant difference in autophagy and apoptosis as compared to the cells incubated in medium with normal glucose, suggesting that high glucose, not high osmolarity, caused autophagy and apoptosis in HK2 cells in a time-dependent manner.

Effect of KIM-1 siRNA on high glucose-induced autophagy and apoptosis in HK-2 cells

We first confirmed the knockdown of KIM-1 expression by KIM-1 siRNA (Fig. 3A and $3 \mathrm{~B})$. In cells treated with high glucose for $24 \mathrm{~h}$, the expression of KIM-1 was increased compared to normal control group. In cells treated with high glucose + KIM-1 siRNA, the expression of KIM-1 was dramatically decreased compared to high glucose group (Fig. $3 \mathrm{~A}$ and 3B). The HK2 cells stimulated with a high concentration of glucose for $24 \mathrm{~h}$ showed significantly increased levels of autophagy and apoptosis compared with normal control group. But these effects of high glucose were significantly blocked by KIM-1 siRNA, which was confirmed by the significantly decreased expression of the LC3-II (Fig. 3A and 3B) and

Fig. 2. Effect of high glucose on autophagy and apoptosis in HK2 cells. (A)Western Blot analysis of LC3II protein levels at 8, 16 and 24 h. (B) Real time PCR analysis of LC3II mRNA levels. (C) Transmission electron microscope observation of autophagosome in different groups (black arrow) (40 000x). (D) Flow cytometry analysis of apoptosis rate in different groups. ${ }^{\mathrm{a}} \mathrm{p}<0.05$ compared with normal control group; ${ }^{b} \mathrm{p}<0.05$ compared with the previous group $(n=3)$.

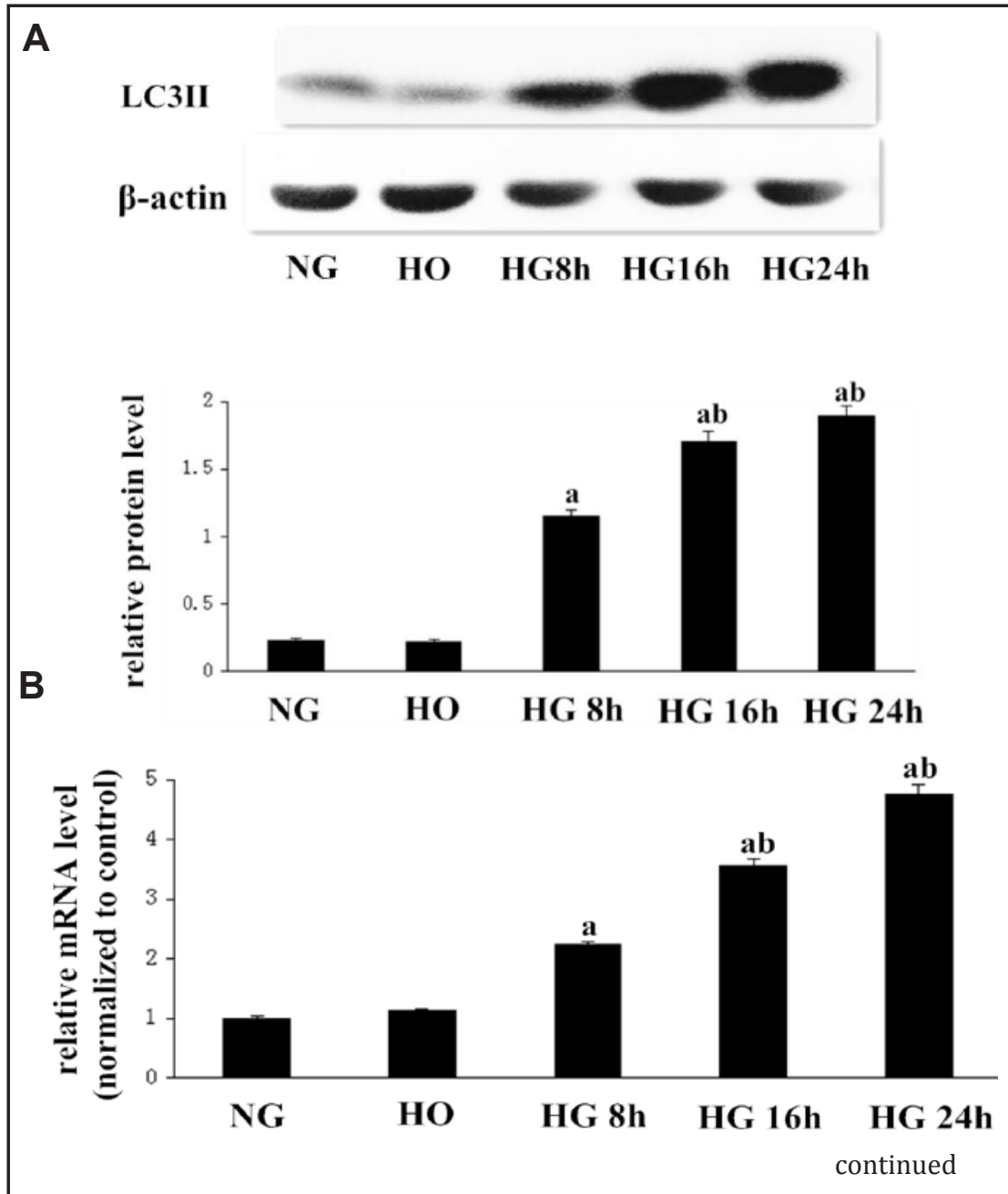



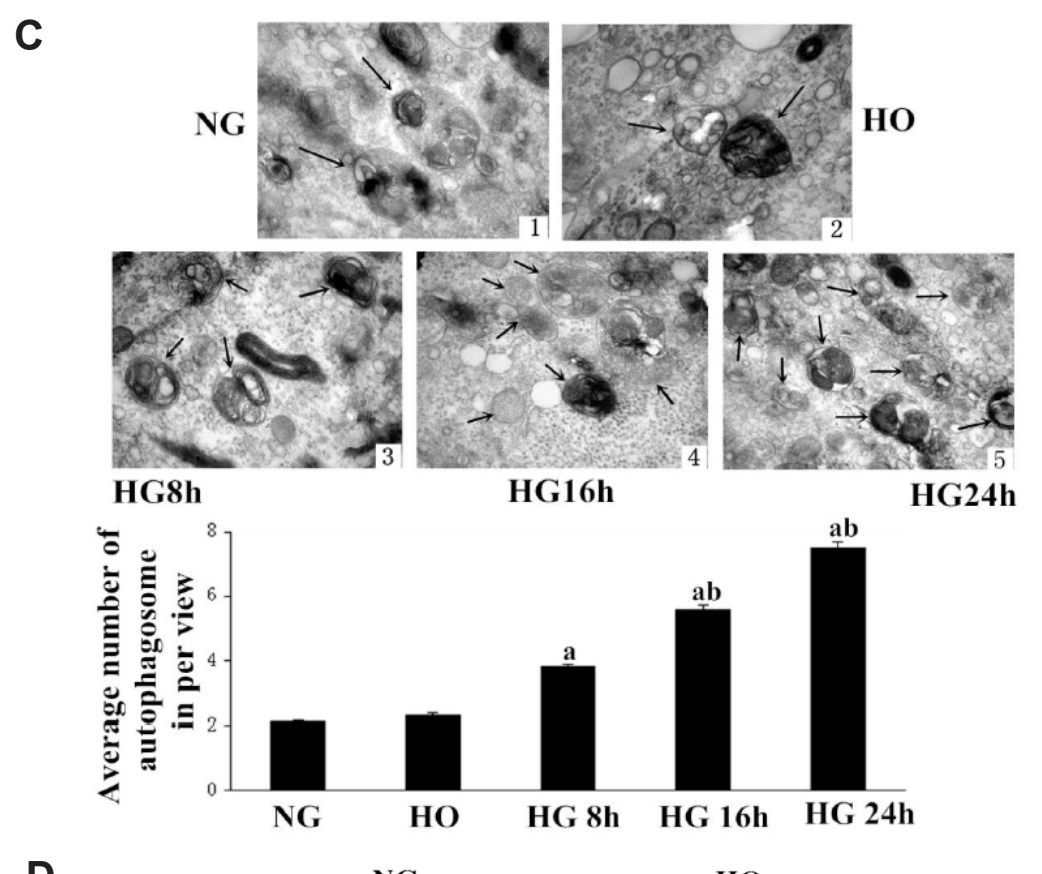

D
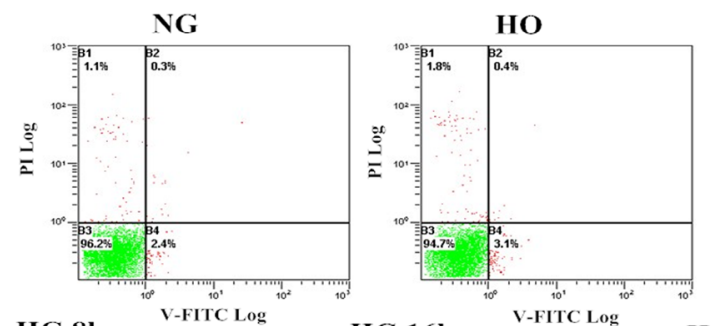
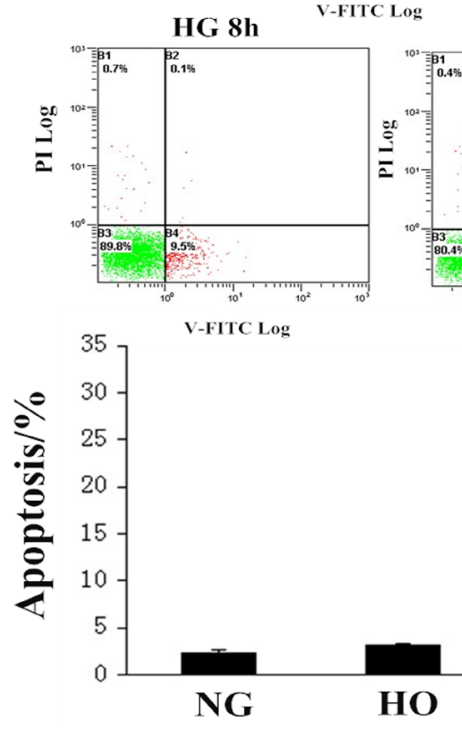

HG 16h
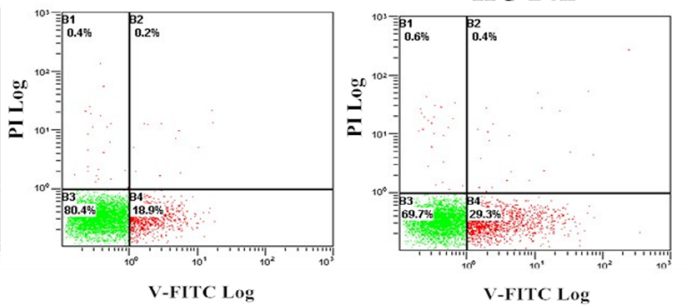

HG 24h

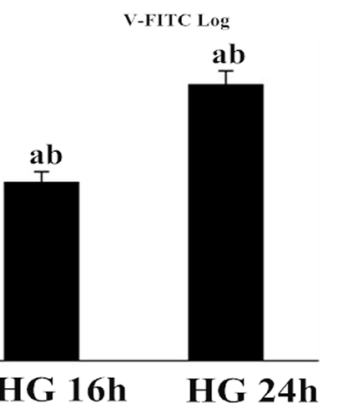

the reduction of autophagosomes formation (Fig. 3C, black arrows). The apoptosis rate of HK2 cells was altered in a similar manner (Fig. 3D).

\section{Discussion}

A number of studies have demonstrated that KIM-1 may participate in the progress of renal injury and repair, as a double-edged sword $[23,24]$. Recent researches have shown that KARGER 
Fig. 3. Effect of KIM-1 SiRNA transfection on autophagy and apoptosis rate in HK2 cells. (A) Western Blot analysis of LC3II protein levels in different groups. (B) Real time PCR analysis of LC3II mRNA levels. (C) Transmission electron microscope observation of autophagosome in different groups (black arrow) (40 000x). (D) Flow cytometry analysis of apoptosis rate in different groups. ${ }^{\mathrm{a}} \mathrm{p}<0.05$ compared with normal control group; ${ }^{\mathrm{b}} \mathrm{p}$ $<0.05$ compared with high glucose group $(n=3)$.
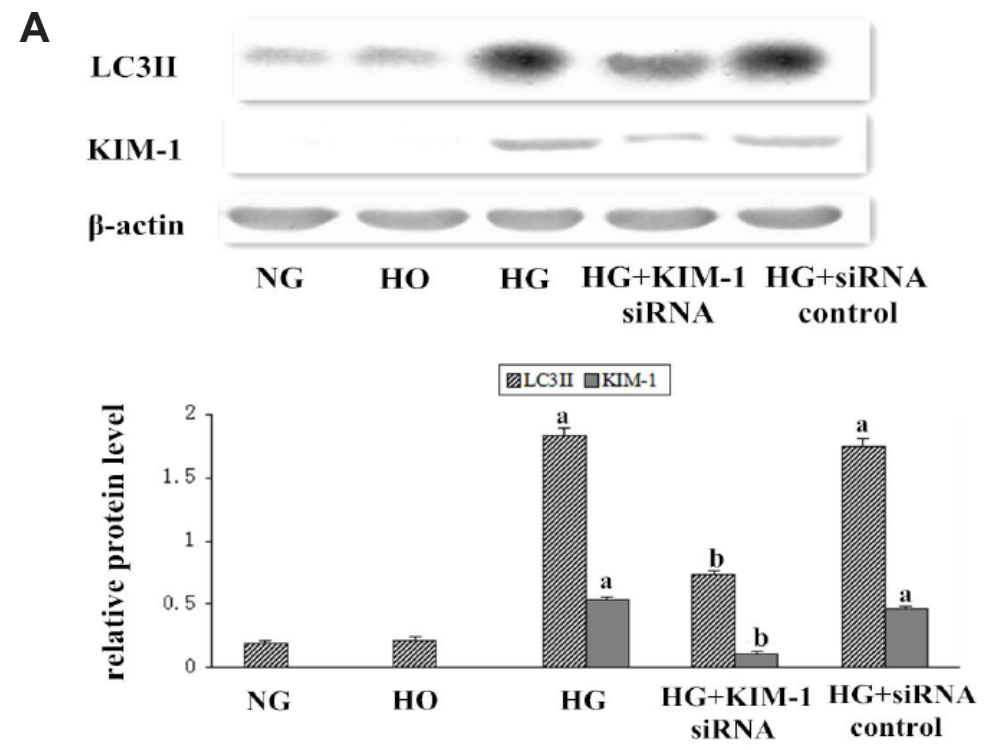

B

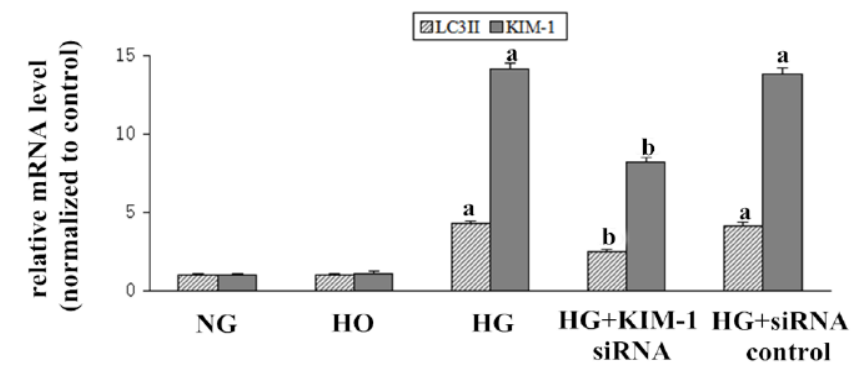

C
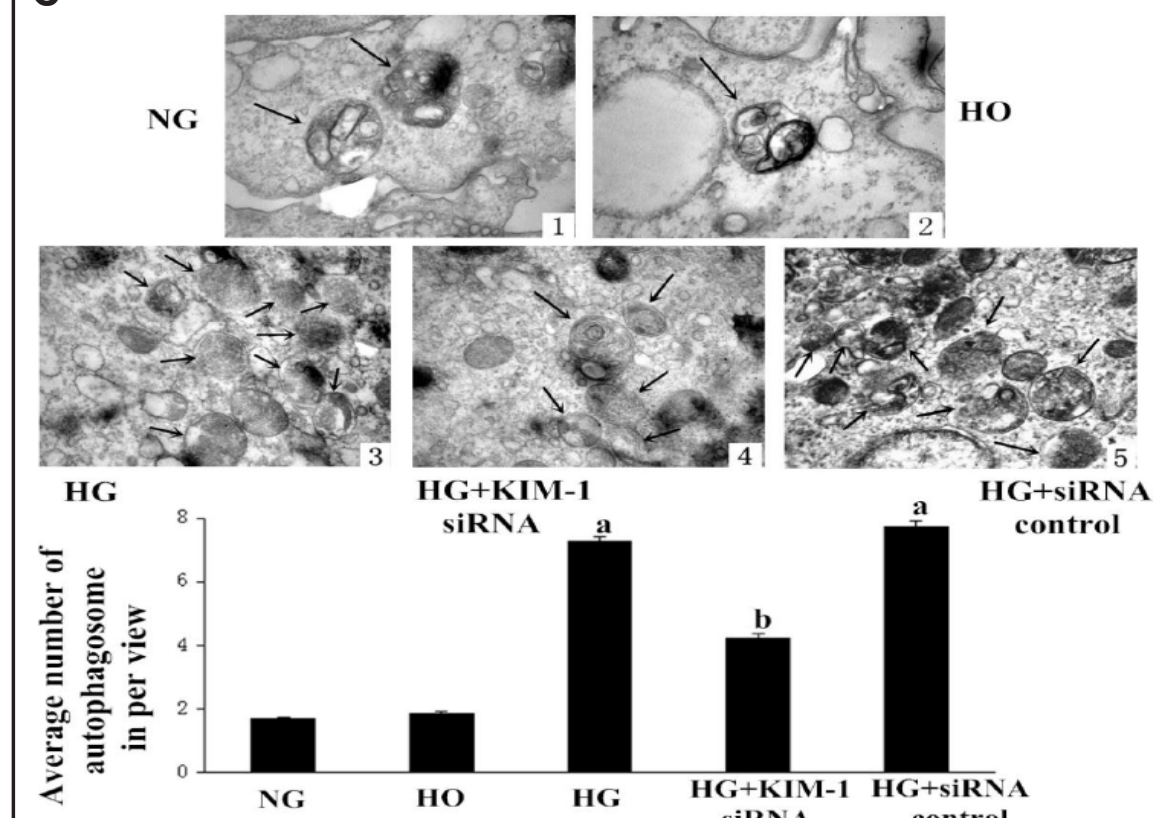

HG+KIM-1

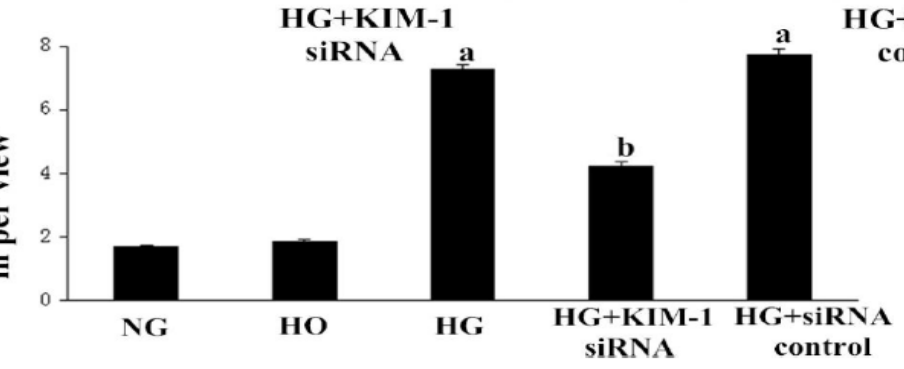

continued

renal KIM-1 and urinary KIM-1 are significantly increased in DN patients [14, 25]. However, whether KIM-1 plays a protective or injurious role in DN progression remain unclear. Our results first showed that high glucose increased the level of KIM-1, autophagy and apoptosis at the same time. When KIM-1 expression interferenced by KIM-1 siRNA, autophagy and 


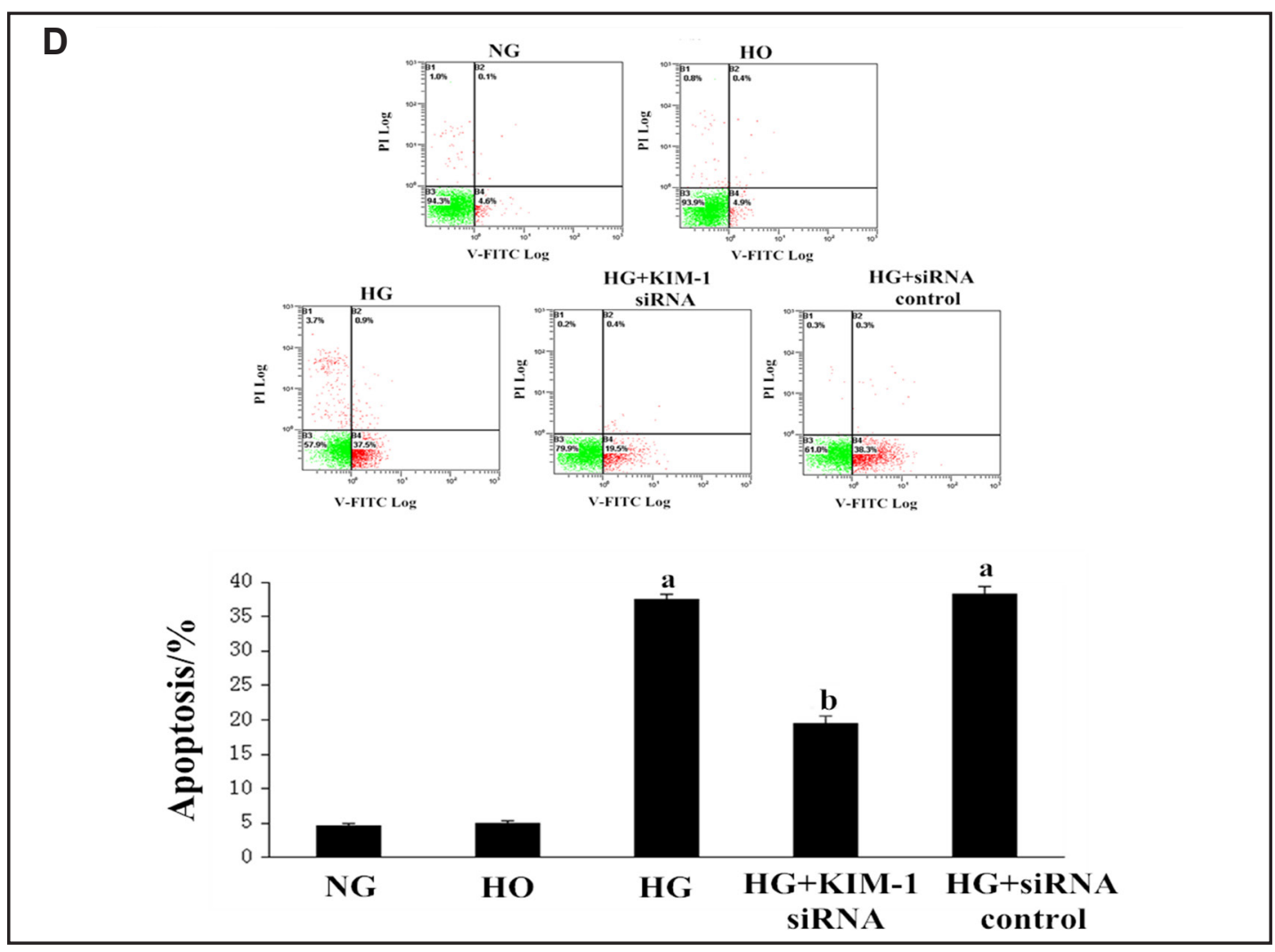

apoptosis of HK2 were significantly reduced, which indicate that KIM-1 may be involved in high glucose-induced damage and repair of renal tubular epithelial cell by regulating cell autophagy and apoptosis.

KIM-1 is well known as a marker of tubular damage[26], its expression and release are induced when renal tubular epithelial cells were injured. Our study show that high glucose increased the level of KIM-1, indicated a high glucose-induced damage in renal tubular cells. However, it is also well recognized that KIM-1 is not only a marker of tubular cell damage but also plays an important role in the mechanisms of renal tubular damage[23]. Many studies have illustrated the different functions of KIM-1, and KIM-1 expression associated with tubulointerstitial inflammation and fibrosis [14]. Our finding that high glucose induced KIM1 may suggest that KIM-1 also participates in high glucose-induced damage in tubular cells.

In order to explore the possible mechanisms, we conducted the further study. Autophagy and apoptosis are two self-destructive processes. Autophagy is a cellular pathway involved in protein and organelle degradation. It plays an important role in cellular homeostasis maintaining. It has been shown that Autophagy plays a renoprotective role during renal Ischemia / Reperfusion Injury [27]. But several lines of evidence have indicated a role for autophagy in promoting cell death [28-30]. As it has been shown that KIM-1 turns tubular cells into semi-professional phagocytes [22], it is possible that increased KIM-1 may enhance the formation of autophagy. To test this hypothesis, we first measured the levels of autophagy. Our results showed that the expression of LC3II (which is associated with the control of autophagosome elongation and used as a marker of autophagy [31]) was markedly increased, the autophagic vacuoles in cytoplasm was markedly accumulated when the HK2 cells were treated with high glucose. Apoptosis is a type of programmed cell death in which the cell responds to certain signals by initiating a normal response that leads to the cell death. Emerging evidence indicates that despite the marked differences between autophagy and apoptosis, their regulation is intimately connected and the same regulators can sometimes control both apoptosis and autophagy [17, 32, 33]. Our findings showed that the number of apoptosis cells was significantly increased when the HK2 cells were treated 


\section{Cellular Physiology Cell Physiol Biochem 2016;38:2479-2488 \begin{tabular}{l|l|l}
\hline DOI: 10.1159/000445598 & $\begin{array}{l}\text { C) 2016 The Author(s). Published by S. Karger AG, Basel } \\
\text { www.karger.com/cpb }\end{array}$
\end{tabular} \\ Gou et al.: KIM-1, Autophagy and Diabetic Nephropathy}

with high glucose. These findings suggested that high glucose has both pro-autophagic and pro-apoptotic effects, and that the changes in autophagy and apoptosis showed the same trends suggested the potential connections in these pathological procedures of high glucoseinduced toxicity in renal tubular epithelial cells.

To determine whether the increased levels of KIM-1 were responsible for the high glucose-induced autophagy and apoptosis, we examined the effect of silencing KIM-1 by siRNA. Our results showed that blocking the increase of KIM-1 attenuated the effects of high glucose on autophagy and apoptosis, suggesting that KIM-1 is the mediator of autophagy and apoptosis induced by high glucose. These data elucidate the mechanism by which KIM-1 produces damage in the renal tubules. As KIM-1 is upregulated in a large variety of chronic kidney diseases, our findings may suggest that KIM-1-mediated autophagic and apoptotic effects are possibly implicated in other forms of chronic renal injuries in addition to DN. The detailed role of KIM-1 in different chronic kidney diseases requires further investigation.

In summary, the results from our study demonstrated that KIM-1 plays an important role in glucose-induced autophagy and apoptosis in HK2 cells. It is concluded that KIM-1 mediated autophagy and apoptosis in renal tubular cells may be an important pathway involved in the pathogenic mechanism of DN. Studies in in vivo experiments are still required in the future.

\section{Acknowledgments}

This work was supported by the National Natural Science Foundation of China (Grant No. 81300605)

\section{Disclosure Statement}

None.

\section{References}

1 Hodgkins KS, Schnaper HW: Tubulointerstitial injury and the progression of chronic kidney disease. Pediatr Nephrol 2012;27:901-909.

2 Yang WS, Kim JS, Han NJ, Lee MJ, Park SK: Toll-like receptor 4/spleen tyrosine kinase complex in high glucose signal transduction of proximal tubular epithelial cells. Cell Physiol Biochem 2015;35:2309-2319.

3 Tang X, Rong G, Bu Y, Zhang S, Zhang M, Zhang J, Liang X: Advanced oxidation protein products induce hypertrophy and epithelial-to-mesenchymal transition in human proximal tubular cells through induction of endoplasmic reticulum stress. Cell Physiol Biochem 2015;35:816-828.

4 Schena FP, Grandaliano G, Gesualdo L: The role of tubular cells in the progression of renal damage: Guilty or innocent? Ren Fail 2001;23:589-596.

5 Allam R, Scherbaum CR, Darisipudi MN, Mulay SR, Hagele H, Lichtnekert J, Hagemann JH, Rupanagudi KV, Ryu M, Schwarzenberger C, Hohenstein B, Hugo C, Uhl B, Reichel CA, Krombach F, Monestier M, Liapis H, Moreth K, Schaefer L, Anders HJ: Histones from dying renal cells aggravate kidney injury via tlr2 and tlr4. J Am Soc Nephrol 2012;23:1375-1388.

6 Benedetti G, Fredriksson L, Herpers B, Meerman J, van de Water B, de Graauw M: Tnf-alpha-mediated nfkappab survival signaling impairment by cisplatin enhances jnk activation allowing synergistic apoptosis of renal proximal tubular cells. Biochem Pharmacol 2013;85:274-286.

7 Marchewka Z, Plonka J: [the diagnostic importance of the new marker kim-1 in kidney damage]. Postepy Hig Med Dosw (Online) 2013;67:695-699.

8 Bonventre JV: Kidney injury molecule-1 (kim-1): A specific and sensitive biomarker of kidney injury. Scand J Clin Lab Invest Suppl 2008;241:78-83.

9 Han WK, Bailly V, Abichandani R, Thadhani R, Bonventre JV: Kidney injury molecule-1 (kim-1): A novel biomarker for human renal proximal tubule injury. Kidney Int 2002;62:237-244.

10 Huo W, Zhang K, Nie Z, Li Q, Jin F: Kidney injury molecule-1 (kim-1): A novel kidney-specific injury molecule playing potential double-edged functions in kidney injury. Transplant Rev (Orlando) 2010;24:143-146. 


\section{Cellular Physiology Cell Physiol Biochem 2016;38:2479-2488 \begin{tabular}{l|l} 
and Biochemistry Published online: June 17, 2016 & $\begin{array}{l}\text { D } 2016 \text { The Author(s). Published by S. Karger AG, Basel } \\
\text { www.karger.com/cpb }\end{array}$
\end{tabular} \\ Gou et al.: KIM-1, Autophagy and Diabetic Nephropathy}

11 Brooks CR, Yeung MY, Brooks YS, Chen H, Ichimura T, Henderson JM, Bonventre JV: Kim-1-/tim-1-mediated phagocytosis links atg5-/ulk1-dependent clearance of apoptotic cells to antigen presentation. EMBO J 2015;34:2441-2464.

12 Bonventre JV: Kidney injury molecule-1: A translational journey. Trans Am Clin Climatol Assoc 2014;125:293-299; discussion 299.

13 Nielsen SE, Schjoedt KJ, Astrup AS, Tarnow L, Lajer M, Hansen PR, Parving HH, Rossing P: Neutrophil gelatinase-associated lipocalin (ngal) and kidney injury molecule 1 (kim1) in patients with diabetic nephropathy: A cross-sectional study and the effects of lisinopril. Diabet Med 2010;27:1144-1150.

14 van Timmeren MM, van den Heuvel MC, Bailly V, Bakker SJ, van Goor H, Stegeman CA: Tubular kidney injury molecule-1 (kim-1) in human renal disease. J Pathol 2007;212:209-217.

15 Prozialeck WC, Edwards JR, Lamar PC, Liu J, Vaidya VS, Bonventre JV: Expression of kidney injury molecule-1 (kim-1) in relation to necrosis and apoptosis during the early stages of cd-induced proximal tubule injury. Toxicol Appl Pharmacol 2009;238:306-314.

16 Maiuri MC, Zalckvar E, Kimchi A, Kroemer G: Self-eating and self-killing: Crosstalk between autophagy and apoptosis. Nat Rev Mol Cell Biol 2007;8:741-752.

17 Marino G, Niso-Santano M, Baehrecke EH, Kroemer G: Self-consumption: The interplay of autophagy and apoptosis. Nat Rev Mol Cell Biol 2014;15:81-94.

18 Wagener FA, Dekker D, Berden JH, Scharstuhl A, van der Vlag J: The role of reactive oxygen species in apoptosis of the diabetic kidney. Apoptosis 2009;14:1451-1458.

19 Gong X, Wang Q Tang X, Wang Y, Fu D, Lu H, Wang G, Norgren S: Tetramethylpyrazine prevents contrastinduced nephropathy by inhibiting p38 mapk and foxo1 signaling pathways. Am J Nephrol 2013;37:199207.

20 Mao S, Zhang J: Role of autophagy in chronic kidney diseases. Int J Clin Exp Med 2015;8:22022-22029.

21 Kume S, Koya D: Autophagy: A novel therapeutic target for diabetic nephropathy. Diabetes Metab J 2015;39:451-460.

22 Ichimura T, Asseldonk EJ, Humphreys BD, Gunaratnam L, Duffield JS, Bonventre JV: Kidney injury molecule-1 is a phosphatidylserine receptor that confers a phagocytic phenotype on epithelial cells. J Clin Invest 2008;118:1657-1668.

23 Humphreys BD, Xu F, Sabbisetti V, Grgic I, Movahedi Naini S, Wang N, Chen G, Xiao S, Patel D, Henderson JM, Ichimura T, Mou S, Soeung S, McMahon AP, Kuchroo VK, Bonventre JV: Chronic epithelial kidney injury molecule-1 expression causes murine kidney fibrosis. J Clin Invest 2013;123:4023-4035.

24 Yang L, Brooks CR, Xiao S, Sabbisetti V, Yeung MY, Hsiao LL, Ichimura T, Kuchroo V, Bonventre JV: Kim-1mediated phagocytosis reduces acute injury to the kidney. J Clin Invest 2015;125:1620-1636.

25 Ahmed SA, Hamed MA: Kidney injury molecule-1 as a predicting factor for inflamed kidney, diabetic and diabetic nephropathy egyptian patients. J Diabetes Metab Disord 2015;14:6.

26 Nakagawa S, Nishihara K, Miyata H, Shinke H, Tomita E, Kajiwara M, Matsubara T, Iehara N, Igarashi Y, Yamada H, Fukatsu A, Yanagita M, Matsubara K, Masuda S: Molecular markers of tubulointerstitial fibrosis and tubular cell damage in patients with chronic kidney disease. PLoS One 2015;10:e0136994.

27 Guan X, Qian Y, Shen Y, Zhang L, Du Y, Dai H, Qian J, Yan Y: Autophagy protects renal tubular cells against ischemia / reperfusion injury in a time-dependent manner. Cell Physiol Biochem 2015;36:285-298.

28 Law BY, Wang M, Ma DL, Al-Mousa F, Michelangeli F, Cheng SH, Ng MH, To KF, Mok AY, Ko RY, Lam SK, Chen F, Che CM, Chiu P, Ko BC: Alisol b, a novel inhibitor of the sarcoplasmic/endoplasmic reticulum $\mathrm{ca}(2+)$ atpase pump, induces autophagy, endoplasmic reticulum stress, and apoptosis. Mol Cancer Ther 2010;9:718-730.

29 Zhu J, Wang KZ, Chu CT: After the banquet: Mitochondrial biogenesis, mitophagy, and cell survival. Autophagy 2013;9:1663-1676.

30 Petersen M, Hofius D, Andersen SU: Signaling unmasked: Autophagy and catalase promote programmed cell death. Autophagy 2014;10:520-521.

31 Ravikumar B, Sarkar S, Davies JE, Futter M, Garcia-Arencibia M, Green-Thompson ZW, Jimenez-Sanchez M, Korolchuk VI, Lichtenberg M, Luo S, Massey DC, Menzies FM, Moreau K, Narayanan U, Renna M, Siddiqi FH, Underwood BR, Winslow AR, Rubinsztein DC: Regulation of mammalian autophagy in physiology and pathophysiology. Physiol Rev 2010;90:1383-1435.

32 Gump JM, Thorburn A: Autophagy and apoptosis: What is the connection? Trends Cell Biol 2011;21:387392.

33 Su M, Mei Y, Sinha S: Role of the crosstalk between autophagy and apoptosis in cancer. J Oncol 2013;2013:102735. 